\title{
Fluorescence-Guided Surgery: A Review on Timing and Use in Brain Tumor Surgery
}

\author{
Alexander J. Schupper ${ }^{1}$, Manasa Rao ${ }^{1}$, Nicki Mohammadi ${ }^{1}$, Rebecca Baron ${ }^{1}$, \\ John Y. K. Lee ${ }^{2}$, Francesco Acerbi ${ }^{3}$ and Constantinos G. Hadjipanayis ${ }^{1 *}$ \\ ${ }^{1}$ Department of Neurosurgery, Icahn School of Medicine at Mount Sinai, New York, NY, United States, ${ }^{2}$ Department of \\ Neurosurgery, University of Pennsylvania School of Medicine, Philadelphia, PA, United States, ${ }^{3}$ Department of Neurosurgery, \\ Fondazione Istituto Di Ricovero e Cura a Carattere Scientifico Istituto Neurologico Carlo Besta, Milan, Italy
}

OPEN ACCESS

Edited by:

Alireza Mansouri,

Pennsylvania State University (PSU),

United States

Reviewed by:

Marco Riva

University of Milan, Italy

Giovanni Raffa,

University of Messina, Italy

*Correspondence:

Constantinos G. Hadjipanayis constantinos.hadjipanayis@ mountsinai.org

Specialty section:

This article was submitted to Neuro-Oncology and Neurosurgical

Oncology,

a section of the journal

Frontiers in Neurology

Received: 17 March 2021

Accepted: 11 May 2021

Published: 16 June 2021

Citation:

Schupper AJ, Rao M, Mohammadi N

Baron R, Lee JYK, Acerbi F and

Hadjipanayis CG (2021)

Fluorescence-Guided Surgery: A

Review on Timing and Use in Brain

Tumor Surgery.

Front. Neurol. 12:682151.

doi: 10.3389/fneur.2021.682151
Fluorescence-guided surgery (FGS) allows surgeons to have improved visualization of tumor tissue in the operating room, enabling maximal safe resection of malignant brain tumors. Over the past two decades, multiple fluorescent agents have been studied for FGS, including 5-aminolevulinic acid (5-ALA), fluorescein sodium, and indocyanine green (ICG). Both non-targeted and targeted fluorescent agents are currently being used in clinical practice, as well as under investigation, for glioma visualization and resection. While the efficacy of intraoperative fluorescence in studied fluorophores has been well established in the literature, the effect of timing on fluorophore administration in glioma surgery has not been as well depicted. In the past year, recent studies of 5-ALA use have shown that intraoperative fluorescence may persist beyond the previously studied window used in prior multicenter trials. Additionally, the use of fluorophores for different brain tumor types is discussed in detail, including a discussion of choosing the right fluorophore based on tumor etiology. In the following review, the authors will describe the temporal nature of the various fluorophores used in glioma surgery, what remains uncertain in FGS, and provide a guide for using fluorescence as a surgical adjunct in brain tumor surgery.

Keywords: fluorescence-guided surgery, 5-ALA, fluorescein, ICG, extent of resection, timing

\section{INTRODUCTION}

The single best prognostic factor for patients diagnosed with high-grade gliomas (HGGs) is maximal resection, also known as gross total surgical resection (GTR) (1-3). HGG GTR has been associated with greater overall survival in addition to longer progression-free survival (PFS) $(1,4)$.In order to maximize the extent of resection (EOR), a number of visualization techniques have been introduced into the field of neurosurgery. Fluorescent agents, also known as fluorophores, aid in the delineation of normal and malignant tumor tissue $(5,6)$, permitting real-time image guided surgery that can maximize EOR (7).

There are a limited number of fluorophores currently used in clinical practice. Stummer first described the use of 5-aminolevulinic acid (5-ALA) and FGS in glioma patients in 1998. Based on the results of a landmark randomized, Phase III study confirming greater tumor resection and better patient outcomes in comparison to conventional microsurgery, 5-ALA (Gleolan) was approved as an oral intraoperative imaging agent for visualization of malignant tissue during glioma surgery $(8-10)$. The fluorophores have various mechanisms of 
action, ranging from intracellular uptake with 5-ALA $(11,12)$ and ICG (13) to extracellular accumulation with fluorescein sodium (FS) and indocyanine-green (ICG), similar to the contrast enhancement found with gadolinium contrast enhancement found with MR imaging (14-16). FS is administered systemically after the induction of anesthesia while ICG and 5-ALA are given several hours before surgery $(11,15,17,18)$ (Table 1).

While each of these agents used for FGS are currently used in patients, there is still ongoing research on the pharmacokinetics of these molecules in order to understand the optimal timing of administration and fluorescence of tumors during surgery. Timing is important with fluorophore administration, as it can be impacted by patient and surgical delays, and may affect the efficacy of the agent. Other new targeted fluorophores are currently being investigated in HGG patients and also require better understanding of optimal administration for FGS. The purpose of this review is to elucidate the current evidence on the perspective of timing for the various fluorophores used in glioma patients for FGS and provide an outline of the literature on the use of the most currently used fluorophores for glioma surgery.

\section{INDOCYANINE GREEN (ICG)}

Indocyanine Green (ICG) has been used widely in medical applications, beginning with hepatic and cardiac function measurement, and expanding into ophthalmology indications where it is FDA approved (Table 2). Upon systemic administration, as an amphiphilic, tricarbocyanine iodide dye, ICG binds to plasma proteins yielding many advantages including its confinement to the vascular compartment (19). Additionally, it's light excitation and emission in the nearinfrared (NIR), low toxicity, and rapid excretion leads to its popularity. ICG has been used as a cerebrovascular intraoperative contrast agent to confirm aneurysm occlusion during surgery. More recently, a more delayed administration of ICG has been described prior to glioma surgery (20). ICG works as a passive targeting agent and requires the breakdown of the $\mathrm{BBB}$ to concentrate at the tumor site (19). Unlike 5-ALA and fluorescein, two popular FDA-approved fluorophore agents, ICG is a near-infrared (NIR) fluorophore which presents unique utility in labeling tumor tissue $(15,21)$. NIR imaging affords higher resolution with increasing tissue penetration depths with excellent signal to noise ratio (SNR) (Figure 1).

Both preclinical and clinical studies report the use of ICG for glioma surgery albeit within a few minutes after systemic administration exploiting vascular permeability of glioma compared to normal brain $(19,22)$. Haglund et al. used ICG for enhanced optical imaging in human gliomas (23). Hansen et al. found that when ICG was injected intravenously into tumor-bearing rats, the tumor fluoresced intensely at 60$120 \mathrm{mg} / \mathrm{kg}$ for at least $1 \mathrm{~h}$ after injection (24). This study showed the ability of ICG to distinguish rat brain tumor from normal parenchyma with adequate tumor to normal brain background ratio, with minimal post-resection residual tumor cells (24).

ICG intrinsic properties include a plasma half-life of 3$4 \mathrm{~min}$; in preclinical studies after $10 \mathrm{~min}$ only a small amount of originally injected ICG volume can be detected in the blood (25). Due to this short half-life, ICG is usually given as a bolus dose of $<0.5-1 \mathrm{mg} / \mathrm{kg}$ and NIR imaging is performed shortly after (23). Haglund et al. found that ICG fluorescence of glioma tissue, unlike fluorescein, is time-dependent (23). Martirosyan et al. found tissue fluorescence when ICG was injected $15 \mathrm{~min}$ prior to visualization, while Haglund et al. found an optical signal between 5 and $10 \mathrm{~min}$ after ICG injection $(23,25)$. The dye uptake rate was shown to be faster in HGGs compared to low-grade gliomas, and this diversity in tumor cell population may explain the time-dependent nature of the ICG peak signal. Studies suggest that as ICG is rapidly being eliminated from the blood at $18-24 \%$ per minute, the dye is sequestered into the tumor (23).

More recently, ICG has been administered at higher doses and tumor visualization has been improved by exploiting the enhanced permeability and retention (EPR) of nanoparticlesized ICG fluorophore within brain tumors (26). Zeh et al. administered doses above the FDA-approved limit of $2 \mathrm{mg} / \mathrm{kg}$ in rodents implanted with human glioma xenografts and demonstrated a broad plateau period extending up to $72 \mathrm{~h}$, thus allowing for optimal imaging of glioma as compared to normal brain (20). With the SWIG approach, combining the natural permeability of the tumor vascularity with poor clearance allows for high doses of ICG to penetrate the tumor, a high dose (5 $\mathrm{mg} / \mathrm{kg}$ ) of intravenous ICG is given a day $(24 \mathrm{~h})$ prior to surgery, yielding improved intraoperative visualization of the tumor compared to white light $(15,27,28)$. In a series of 15 gliomas featuring $11 \mathrm{HGG}$, sensitivity was $98 \%$ and specificity $45 \%$ (27).

\section{FLUORESCEIN SODIUM}

Fluorescein sodium (FS) is best known for its use in ophthalmology where it is FDA approved for angiography or angioscopy of the retina and iris vasculature (FDA approval letter). Recently, it has been reintroduced into neuro-oncologic surgery for HGG FGS. FS has a molecular weight of 376.27 and is the sodium salt of fluorescein. It was first used to visualize malignant brain tumor in 1948 (29). FS accumulates in HGGs where the $\mathrm{BBB}$ is disrupted and provides intra-operative visualization that is similar to pre-operative contrast-enhanced T1 images in which gadolinium accumulation is seen (30-33). FS can be viewed under white light, but the use of an operating microscope fitted with a dedicated filter allows to significantly reduce the dose needed to highlight tumoral tissue (Figure 2) $(19,30,31,34)$. FS is excited at $460-500 \mathrm{~nm}$ and emits a green, fluorescent emission wavelength at $540-690 \mathrm{~nm}(19,35)$. FS is administered at the time of anesthesia prior to a craniotomy for HGG FGS. Immediately after systemic administration FS flows within the cerebral vasculature and afterwards accumulates in tumoral area where there is a damage of BBB. Fluorescence by FS can be visualized for up to $4 \mathrm{~h}$ after administration.

Both preclinical and clinical studies have confirmed that fluorescein, unlike other fluorophores, does not accumulate intracellularly but in the extracellular space in brain tumors (32, 35-37). Instead of tumor-specific uptake, it has been 
TABLE 1 | Summary of the properties of fluorophores currently used in fluorescence-guided surgery.

\begin{tabular}{|c|c|c|c|c|c|c|c|c|}
\hline Agent & $\begin{array}{l}\text { Excitation } \\
\text { (nm) }\end{array}$ & $\begin{array}{l}\text { Emission } \\
\text { (nm) }\end{array}$ & $\begin{array}{l}\text { Targeting } \\
\text { mode }\end{array}$ & $\begin{array}{l}\text { Administration } \\
\text { mode }\end{array}$ & $\begin{array}{l}\text { Dosage (in } \\
\text { humans) }\end{array}$ & Half-life & $\begin{array}{l}\text { Time prior to } \\
\text { visualization }\end{array}$ & $\begin{array}{l}\text { Time to fluorescence } \\
\text { disappearing in target } \\
\text { tissue }\end{array}$ \\
\hline ICG & 778 & $700-850$ & Passive & IV & $0.2-5 \mathrm{mg} / \mathrm{kg}$ & $3-4 \min$ & Seconds & Several minutes \\
\hline Second Window ICG & 778 & $700-850$ & Passive & IV & $2.5-5.0 \mathrm{mg} / \mathrm{kg}$ & & $24 \mathrm{~h}$ & $>72 \mathrm{~h}$ \\
\hline Fluorescein & $460-500$ & $540-690$ & Passive & IV & $2-20 \mathrm{mg} / \mathrm{kg}$ & $23.5 \mathrm{~min}$ & $2-4 h$ & $2-4 \mathrm{~h}$ \\
\hline 5-ALA & $375-440$ & $640-710$ & Metabolic & Oral & $20 \mathrm{mg} / \mathrm{kg}$ & $1-3 h$ & $2-8 \mathrm{~h}$ & $22 \mathrm{~h}$ \\
\hline BᄂZ-100 & 785 & $700-850$ & Molecular & IV & $3-30 \mathrm{mg}$ & $30 \mathrm{~min}$ & $3-29 h$ & $48 \mathrm{~h}$ \\
\hline CLR1501 & 500 & 517 & Molecular & IV & $16 \mathrm{mg} / \mathrm{kg}$ & 4 days & 4 days & - \\
\hline CLR1502 & 760 & 778 & Molecular & IV & $2 \mathrm{mg} / \mathrm{kg}$ & 4 days & 4 days & - \\
\hline IRDye800CW (EGFR) & - & 794 & Molecular & IV & Up to 24.5 mg/kg & $15-20 \min$ & $1 \mathrm{~h}$ & 3-4 days \\
\hline
\end{tabular}

ICG, indocyanine green; 5-ALA, 5-aminolevulinic acid; IV, intravenous.

TABLE 2 | Fluorophores currently used in brain tumor surgery and Food and Drug Administration (FDA) use approval.

\begin{tabular}{|c|c|c|}
\hline Agent & Year of FDA approval & Use of FDA approval \\
\hline ICG & 1959 & $\begin{array}{l}\text { 1. Determining cardiac output, hepatic function and liver blood } \\
\text { flow. } \\
\text { 2. For ophthalmic angiography. }\end{array}$ \\
\hline Fluorescein & 2006 & $\begin{array}{l}\text { 1. Diagnostic fluorescein angiography or angioscopy of the } \\
\text { retina and iris vasculature. }\end{array}$ \\
\hline 5-ALA & 2017 & $\begin{array}{l}\text { 1. Intraoperative optical imaging agent in patients with } \\
\text { suspected high-grade gliomas }\end{array}$ \\
\hline
\end{tabular}

FDA, Food and Drug Administration; ICG, indocyanine green; 5-ALA, 5-aminolevulinic acid.

demonstrated that fluorescein sodium accumulates at disruptions of the $\mathrm{BBB}$ in areas with high- density tumor cells, thereby proving useful for HGG visualization $(30-33,36,37)$. Fluorescein sodium has been found to have a sensitivity of $82-94 \%$ and a specificity of $90-91 \%$ for glioma visualization $(19,31,32,38)$. However, it has also been shown that FS fluorescence might not be limited to tumor tissue. As a matter of fact, some areas, such as dura mater, circumventricular organs and choroid plexus, due to the lack of $\mathrm{BBB}$, appears intensively fluorescent (35). In addition, although the presence of FS fluorescence in normal brain parenchyma close to tumor tissue has been occasionally shown and considered a consequence of direct surgical manipulation $(33,39-41)$, it has been suggested that the application of a strict intraoperative protocol of FS injection could significantly limit this event (35).

Many studies have reported the safety, efficacy, and convenience of using fluorescein sodium during HGG resection (7, 16, 31, 35, 42-46). Maximal resection or gross-total resection (GTR) of tumors with FS has been reported with an increase in progression-free survival (PFS) (16, 19, 31$33,35,39,40,44,45,47)$. Additionally, due to concern that fluorescein is non-selective for tumor tissue, one study concluded that dual labeling with 5-ALA and fluorescein allowed for superior visualization in high-grade glioma resection because fluorescein sodium enhanced background tissue and 5-ALA enhanced tumor tissue (48).

Few studies have reported guidelines on when to administer FS for best visualization in the surgical field. Fluorescein distributes to tissues within $10 \mathrm{~min}$ and has a plasma halflife of $23.5 \mathrm{~min}$ (49). In clinical practice, FS is administered systemically in the operating room either immediately after anesthesia induction or prior to surgical resection $(7,16,18,31,33,35,39,42,45,49,50)$. In order to elucidate whether fluorescein can be seen in non-tumor tissue, one study evaluated the pharmacokinetics of fluorescein sodium in different preclinical mouse models, without and with xenograft tumor (51). This study established that the majority (up to 70\%) of injected fluorescein exists in circulating blood in the unbound form and that only up to $30 \%$ result to be protein-bound. Due to its low molecular weight, the circulating unbound form accumulates in normal mice brain tissue without xenograft tumor, with a peak timing of 30 min after injection, particularly if injected at human-equivalent high dosage, and that washout from normal brain seems to be completed $120 \mathrm{~min}$ after fluorescein injection. When used in orthotopic glioma models, the presence of unbound fluorescein in normal brain tissue $60 \mathrm{~min}$ after injection significantly reduces the tumor-to-normal contrast (51). The study also elucidated the fact that pegylated fluorescein sodium, which better matches gadolinium contrast in sizing, seems to provide more suitable kinetics and a higher ratio of tumor fluorescence compared to normal brain tissue in othotopic glioma models (51). There is a paucity of clinical data on the best timing of FS administration. Some studies have reported administration of fluorescein after incision of the dura with resection beginning as early as 10 or $20 \mathrm{~min}$ after injection $(7,16,33,39,42,44)$. However, in more recent 


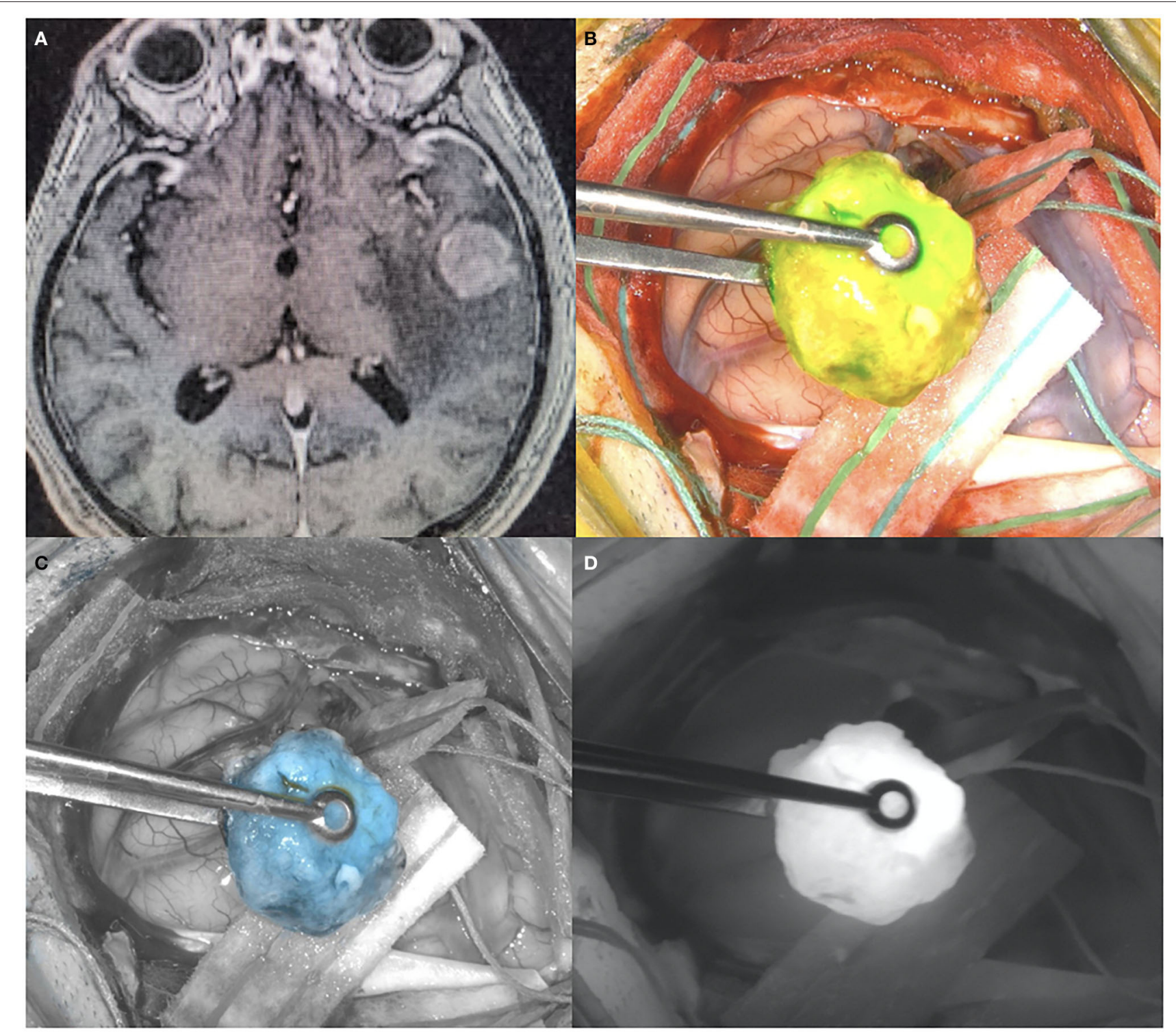

FIGURE 1 | (A) Pre-operative T1 post-contrast MR, showing a left temporal lesion with surrounding vasogenic edema. Histological diagnosis showed a metastatic lung adenocarcinoma. (B) Intraoperative picture during the surgical removal of the same case depicted in (A), showing the ICG uptake by the tumor visualized with yellow-green excitation. (C) Intraoperative picture during the surgical removal of the same case depicted in (A), showing the ICG uptake by the tumor with blue excitation. (D) Intraoperative picture during the surgical removal of the same case depicted in (A), showing the ICG uptake by the tumor visualized with near-infrared excitation.

experiences it has been suggested to use low dose $(5 \mathrm{mg} / \mathrm{kg})$ of fluorescein, with intravenous injection performed after patient intubation, thus in most of the cases around $1 \mathrm{~h}$ before incision of dura mater $(18,31,35)$. More specifically, it has been shown that the optimal strategy to optimize fluorescent contrast during surgery is to use lower dose $(1-5 \mathrm{mg} / \mathrm{kg})$ to minimize unspecific extravasation, administered $2-4 \mathrm{~h}$ before visualization, which corresponds to the wash-out period of the FLS (43). Surely, a need for further investigation of the clinicallyrelevant pharmacokinetics of optimal fluorescein sodium administration remains.

\section{5-AMINOLEVULINIC ACID (5-ALA)}

5-ALA, a precursor metabolized in the heme biosynthesis pathway to protoporphyrin (PPIX), accumulates intracellularly in tumor cells, and has a high affinity for high-grade glioma tissue (52). PPIX absorbs light between 375 and $440 \mathrm{~nm}$ and emits a violet-red fluorescence at $635 \mathrm{~nm}$ (Figure 3) (11) 5-ALA is the most well-studied fluorescent agent in glioma surgery that has been granted FDA approval $(54,55)$. A landmark randomized controlled study (RCT) was performed where HGG patients were randomized to FGS or conventional microsurgery (8) 5-ALA FGS 


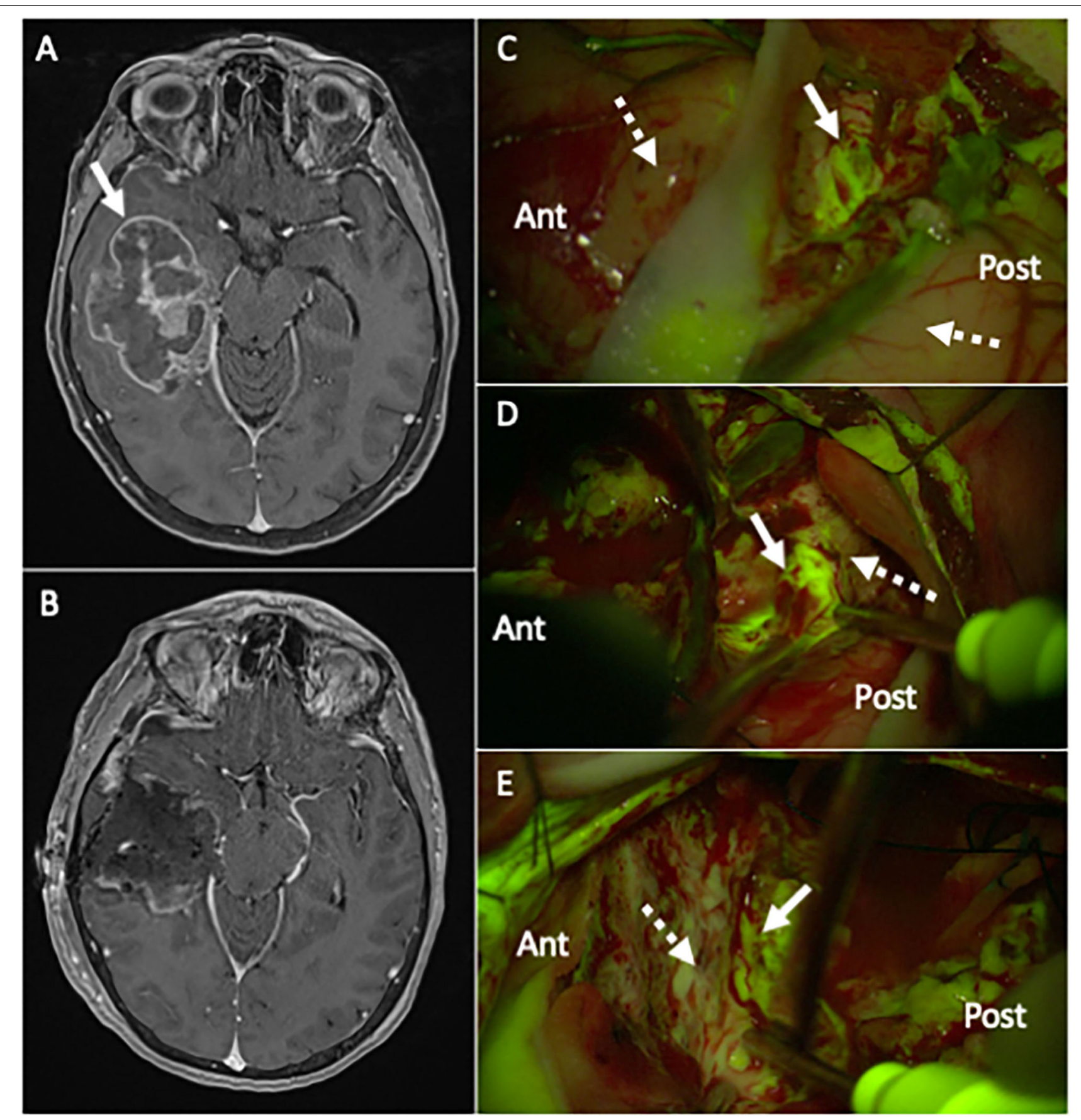

FIGURE 2 | (A) Pre-operative T1 post-contrast MR, showing a large right temporal lesion (white arrow), with irregular enhancement and mass effect, compatible with the suspect of high-grade glioma. (B) Post-operative T1 post-contrast MR, performed $24 \mathrm{~h}$ after surgery, confirming a gross-total resection (GTR) of the lesion (histological diagnosis showed a Glioblastoma, IDH wild-type). (C-E) Intraoperative picture during the surgical removal of the same case depicted in (A), taken with the Y560 filter activated (Pentero 900 microscope, Carl Zeiss Meditec, Oberkochen, Germany): after a small corticectomy (C), the pathological tissue is clearly visible as a bright green-yellow fluorescent area (white arrow), while the non-pathological temporal cortex (dotted white arrow) anteriorly and posteriorly is non-fluorescent (for orientation, Ant is anterior and Post is posterior temporal lobe); during surgical removal with ultrasonic aspirator (Sonoca 300, Soring, Quickborn, Germany), subcortical tumoral tissue is clearly discernible from normal peri-tumoral parenchyma by its bright green-yellow fluorescence (white arrow in (D) at the posterior border and in (E) at the anterior border), compared to pinkish peritumoral parenchyma (dotted white arrow). 
was associated with improved progression-free survival (PFS) and greater overall tumor resection compared to white light control. 5-ALA FGS has been shown to be both safe and effective, with minimal side effects $(8,56,57)$.

Since the publication of the RCT, the widespread use of 5ALA globally has been based upon the same drug administration criteria used in the trial. An oral dose of ALA HCL solution of $20 \mathrm{mg} / \mathrm{kg}$ body weight, is administered $3 \mathrm{~h}$ (range $2-4 \mathrm{~h}$ ) prior to induction of anesthesia (8) 5-ALA is rapidly absorbed into the blood after ingestion within $1 \mathrm{~h}$ and is metabolized quickly thereafter in brain tumors to its fluorescent PPIX metabolite. This dosing regimen was based upon rodent experiments in which there was a fluorescence peak observed $6 \mathrm{~h}$ after administration (10). The decision to have the patient ingest the medication at $3 \mathrm{~h}$ (with a range of $2-4 \mathrm{~h}$ ) prior to surgery was recommended to allow ample time for anesthesia, monitoring and performing the craniotomy, in order for peak intraoperative PPIX fluorescence to be present during tumor resection $(8,56)$. As a result of this RCT and other European multicenter trials, the same administration criterion was used for the Food and Drug Administration (FDA) approval of 5-ALA (Gleolan ${ }^{\circledR}$ ) in 2017 [(54); FDA approval] (58).

Recent studies have suggested that 5-ALA fluorescence may have a longer window of detection than previously described. In a prospective study of 68 patients and 201 tumor samples, Kaneko et al. found that maximal fluorescence intensity was observed 7-8 $\mathrm{h}$ following 5-ALA administration, and weak fluorescence peaked later than strong fluorescence, at 8-9 h (59). While prior animal studies have suggested an earlier fluorescence peak, there is now evidence that a longer latency time might lead to stronger fluorescence of HGG tissue. In a retrospective study of 16 patients who received 5-ALA over $4 \mathrm{~h}$ prior to anesthesia induction, our group found that adequate intraoperative fluorescence was seen up to almost $28 \mathrm{~h}$ post-ingestion, with no 5-ALArelated toxicity (53). Understanding the time window for 5ALA PpIX fluorescence is clinically relevant, as surgeries are not uncommonly delayed due to emergent cases, staffing issues or other logistical challenges, and it is important to know if intraoperative fluorescence may be utilized despite delays in surgery. Unlike fluorescein and ICG which may be given in the operating room after induction of anesthesia, 5-ALA requires oral administration, and therefore there exists an element of anticipating time of surgery. Having a less narrow window of adequate intraoperative fluorescence allows surgeons greater flexibility with using 5-ALA for glioma surgery.

\section{TARGETED FLUOROPHORES}

In addition to the fluorophores mentioned above, there are current studies on fluorophores with more directed mechanisms of action, such as specific receptor targets. Below is a description of several targeted agents currently under clinical investigation.

\section{BLZ-100}

A conjugate of tumor-specific peptide chlorotoxin paired with a near-infrared fluorophore, BLZ-100 (tozuleristide, Blaze Bioscience Inc, Seattle, Washington) is visualized with a NIR camera (60). A recent phase I trial demonstrated safety and efficacy for the use of BLZ-100 in patients with primary and recurrent glioblastoma (60). Ongoing evaluation of the conjugate is currently being studied in both adult and pediatric brain tumors (NCT02234297, NCT02462629). BLZ-100 has the same benefits as ICG in the NIR spectrum, however, it adds further tumor specificity with chlorotoxin, a scorpion venom. Given intravenously, BLZ-100, also known as The Tumor Paint ${ }^{\circledR}$, can safely be given to adults in doses ranging from 3 to $30 \mathrm{mg}$ (60). In this trial, BLZ-100 was administered as a slow IV bolus injection over $1-5 \mathrm{~min} 3-29 \mathrm{~h}$ before surgery. It has a serum halflife of $\sim 30 \mathrm{~min}$, however, unlike 5-ALA, has been shown to be retained in tumors for over $24 \mathrm{~h}$, particularly in doses over $9 \mathrm{mg}$ or greater in World Health Organization (WHO) grade III and IV gliomas (60). Its length of time in tumor tissue is currently unknown. Further study is required on a larger patient sample, however, depending upon the sensitivity of specificity of BLZ100 , it may provide a useful fluorophore given its high intensity of fluorescence and prolonged retention in glioma tissue.

\section{Alkyl Phosphocholine Analogs}

Alkylphosphocholine analogs (APCs) are small synthetic phospholipid ether molecules, which may target specific tumors types, including osteosarcoma, pancreatic adenocarcinoma and glioblastoma (61). Due to lipid raft expression, APCs are able to remain intracellular for prolonged periods of time (61), providing a theoretical advantage for FGS. To date, there are no published clinical results on APC use in gliomas, however, in a proof-of-principle preclinical study, high glioblastoma cell selectivity has been shown with two APCs (CLR1501 and CLR1502, Cellectar Biosciences, Madison, Wisconsin) (62). In the xenograft model, the two APCs were given intravenously in doses ranging from 2 to 16 $\mathrm{mg} / \mathrm{kg} 4$ days prior to sacrifice. CLR1501 (green spectrum) showed a tumor to brain fluorescence ratio comparable to 5-ALA, while CLR1502 (NIR) had a superior tumor to brain fluorescence ratio (62).

\section{Epidermal Growth Factor Receptor (EGFR) Targeted Fluorophores}

Expressed as cell-surface receptors in many cancers including gliomas, epidermal growth factor receptor (EGFR) may be conjugated with fluorescent dyes, allowing for targeted cellsurface fluorescence (63). In an in vivo animal study of IRDye800CW labeled with anti-EGFR antibodies, there was a $100 \%$ sensitivity and specificity for distinguishing GBM-specific mutated EGFR positive from EGFR negative cell lines (64). While no clinical studies have been performed to date, preclinical studies have administered intravenous anti-EGFR fluorescence conjugates into rats, and observed safe doses up to $24.5 \mathrm{mg} / \mathrm{kg}$ of an IRDye800CW anti-EGFR antibody (ABY-029, Affibody, Sweden) (65). However, due to its short half-life it will need to be given during surgery in humans, and in preclinical investigation had poor fluorescent intensity in the brain (65). Based upon this preclinical trial, it was determined that ABY-029 can be administered within minutes to hours of the surgery start time, and fluorescence was still observed $48 \mathrm{~h}$ post-administration (66). 


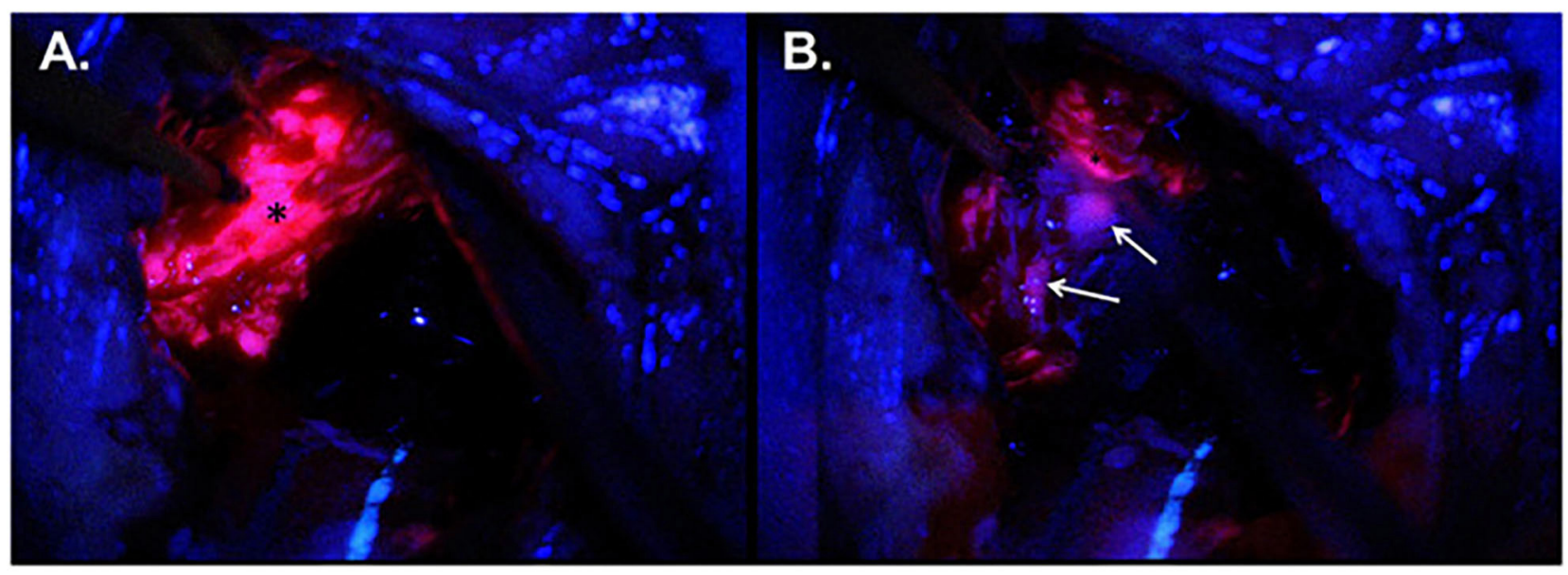

FIGURE 3 | Intraoperative imaging for case demonstration patient. (A) Tumor bulk fluorescence after 5-ALA administration (asterisk). (B) Infiltrative margin fluorescence after 5-ALA administration (white arrows). Taken with permission from Maragkos et al. (53).

Cetuximab, an EGFR monoclonal antibody, when conjugated with fluorescent IRDye $800 \mathrm{CW}$, fluoresces in the NIR, and has been shown in preclinical studies to be effective for glioma surgery (67). In a first-in-human study, cetuximab-IRDye800 demonstrated both safety and efficacy, with high signal to background ration aiding in glioblastoma visualization (68). Larger studies are warranted to better underwent the use of cetuximab conjugates for FGS.

\section{CHOOSING THE RIGHT FLUOROPHORES: PROPOSED SUGGESTIONS}

While all fluorophores provide varying degrees of intraoperative fluorescence during brain tumor surgery, the various mechanisms of action make certain fluorophores better choices for different tumor types. Below is an outline for the different fluorophores currently available for use in FGS, based upon tumor pathology.

\section{High-Grade Gliomas}

High-grade gliomas (HGG) are the most widely studied tumor type in FGS. The three most commonly studied fluorophores, 5ALA, fluorescein and ICG, have all been used in HGG surgery. 5-ALA has been the most robustly studied fluorophore in malignant gliomas. PPIX specifically accumulates in the tumor intracellular space, resulting in a robust red fluorescence in the tumor bulk, and a surrounding lighter pink fluorescence peripherally, representing surrounding infiltrative tumor cells $(69,70)$. This selective uptake in tumor cells results in high sensitivity and specficity, with prior studies showing mean sensitivity and specificity for delineating tumor tissue vs. surrounding brain to be $83-87 \%$ and $89-100 \%$, respectively (6, 10, 71, 72). Additionally, 5-ALA has a strong positive predictive value, with multiple studies finding 100\% PPV for solid fluorescence in both primary and recurrent HGG (70, 73,
74). Beyond histologic accuracy of 5-ALA PPIX fluorescence, correlations have been made between fluorescence intensity and histological grading, suggesting the ability to approximate grade by fluorescent signal $(75,76)$.

In addition to being safe for use in HGG surgery, 5-ALA has also shown to improve patient outcomes. In a phase III randomized controlled trial of $322 \mathrm{HGG}$ patients randomized to 5-ALA FGS or white light surgery, Stummer et al. found that patients who received 5-ALA experience more complete resections of contrast-enhancing tumor ( 65 vs. $36 \%, p<0.0001$ ), and higher 6-month progression-free survival ( 41.0 vs. $21.1 \%, p$ $=0.0003$ ) (8). In a retrospective study of glioblastoma patients that had undergone surgery with 5-ALA, those patients without residual tissue fluorescence had greater median overall survival compared to those with residual fluorescence ( 27 vs. 17.5 months, $p=0.015)(77)$.

Despite the advantages of 5-ALA for HGG surgery, the agent is expensive and not universally available. Following a series of successful clinical trials in 5-ALA, FGS researchers tested the safety and efficacy of other more widely accessible fluorophores for HGG resections. Several recent studies have assessed the use of fluorescein sodium, and found that fluorescein improves extent of resection and rates of gross total resection, with GTR rates up to $80 \%(7,30,31,78)$. Despite being selective for areas of blood-brain barrier breakdown, rather than tumor tissue itself, fluorescein fluorescent signal has been shown to correlate with contrast-enhancement on preoperative MR imaging $(32,40)$. To date, there are no randomized controlled trials for fluoresceinguided tumor surgery, however, in a recent multicenter phase II study, Acerbi et al. found that fluorescein was safe and effective in HGG surgery, with a GTR rate of $82.6 \%$ and 6-month progression-free survival of 56.6\% (35). ICG, a fluorophore used primarily in angiography, has recently been implemented in brain tumor surgery, for its enhanced permeability retention (EPR) effect as a result of $\mathrm{BBB}$ disruption. The second window ICG (SWIG) technique allows for ICG accumulation in HGG 
tissue, allowing for improved visualization $(15,28)$. While this technique has not yet been widely studies, in a recent case series of 11 HGG, SWIG was found to be highly sensitive for HGG tissue, and fluorescent signal correlated with MR imaging (27). While safely tolerated, the major disadvtange of ICG is that unlike 5-ALA and fluorescein, it emits in the near infrared spectrum, making it logistically difficult to operate while visualizing the signal.

\section{Low-Grade Gliomas}

Low-grade gliomas have created a larger challenge for FGS compared to HGG, as the lower grade tumors do not have as robust areas of BBB breakdown and contrast uptake compared to more infiltrative lesions. While historically "watch and wait" was the treatment paradigm for these lesions, there is now strong evidence for early, maximal safe resection $(74,79,80)$. However, these tumors may be difficult to remove completely, as their appearance may only appear slightly different compared to normal brain, and therefore 5-ALA has been implemented. While initially researchers were doubtful that there would be any 5-ALA PPIX uptake in LGG cells due to less BBB breakdown, the differences appear quantitative, rather than qualitative (81). Although initial studies showed no fluorescence in LGG patients $(82,83)$. Widhalm et al. found a subset of non-contrastenhancing LGG patients with 5-ALA-induced fluorescence (84). In the largest series to date, Jaber et al. found visible fluorescence in only 13 of 82 WHO grade II gliomas, and concluded that the majority of LGG do not show visible fluorescence (85). However, the value in use of 5-ALA for LGG surgery may be in the histological heterogeneity of these tumors, as areas of malignant transformation, or anaplastic foci, are characteristic for LGGs (86). By fluorescing areas of contrast-enhancement, 5-ALA can help identify areas of higher metabolic activity and subsequently greater proliferation (87).

\section{Meningiomas}

Meningiomas are the most common benign brain tumors, and with the propensity to enhance on contrasted imaging, they have been studied in the field of FGS. While the three major fluorophores, 5-ALA, ICG, and fluorescein, have all been studied in the visualization of meningiomas, 5-ALA has been most widely studied, with over 10 clinical studies to date (88). The largest study of FGS use in meningiomas is by Millesi et al., where after administration of 5-ALA to 204 meningioma patients, visible fluorescent signal was found in $91 \%$ of tumors, and $100 \%$ positive preductive value for bone infiltration (89). In a study of 12 meningioma patients, seven skull base and five convexity, Della Puppa et al. found $89 \%$ sensitivity and $100 \%$ specificity for 5 ALA detecting bone invasion (90). Additionally, in a small series of eight intradural spinal meningiomas using 5-ALA, there was a positive predictive value of $100 \%$ (91).

ICG and fluorescein have also been used in the resection of meningiomas. ICG in particular has been found to be helpful in cases where the tumor invades the dural sinuses, and helps visualize venous collaterals, the surrounding patent sinuses and the pial vascular supply (92-94). In these cases, however, ICG is being used as a vascular contrast agent with visualization within minutes of IV bolus dosing. In contrast, Lee et al., employed the high dose, delayed second window ICG technique found that $78 \%$ meningiomas exhibited more fluorescent signal than surrounding brain, with a sensitivity of $96.4 \%$, but only $39 \%$ specificity (95). Fluorescein, like ICG, accumulates within tumor regions rapidly, however, the fluorescent signal may persist for hours, aiding in the visualization of meningiomas (54). In a recent study of 30 patients with meningiomas undergoing resection, Akcakaya et al. found that $88 \%$ of meningiomas demonstrate diffuse homogenous intraoperative enhancement, yielding a resection rate of $87 \%$ (96). With fluorescein, confocal microscopy can help illuminate meningiomas on the cellular level, with a confocal/histology concordance of $90 \%$, with identification of dural invasion (97).

\section{Brain Metastases}

As the most common brain tumors in adults, the treatment paradigm for cerebral metastases has been widely studied. Depending on the size, location and quantity of CNS metastatic lesions, treatment options may include chemotherapy, radiation modalities such as stereotactic radiosurgery (SRS) and whole brain radiation therapy (WBRT), and surgical resection. For symptomatic tumors causing mass effect and cerebral compression, complete resection of metastatic lesions is always the goal when attainable (98). Despite the non-infiltrative nature of these lesions (compared to gliomas), 30\% of resections are incomplete, which may explain the $60 \%$ local recurrence rate $(99,100)$, providing a rationale for use of an adjunct such as FGS.

5-ALA has been shown to fluoresce in metastatic lung, breast, colon, bladder, melanoma and other primary cancers with brain metastases (101-104). First studied in 2007, 5ALA for brain metastases has not been widely studied, with only several large patient studies $(54,105)$. In the largest experience to date of 157 patients with known metastatic lesions undergoing resection with 5-ALA, Marhold et al. concluded that $66 \%$ of tumors exhibited fluorescence, with ductal breast cancer having the highest rate of fluorescence (106). In addition to having variable rates of fluorescence, 5-ALA has shown fluorescence in extra-tumoral edema in cases where the tumor core demonstrated poor fluorescence, making FGS less reliable in these cases (107). Further study is warranted on determining predictors of fluorescence among different primary cancers with brain metastases, as well as a more specified use for FGS in metastatic disease.

Fluorescein sodium has been broadly studied for its use in resection of brain metastases. In a series of 30 patients, Schebesch et al. found fluorescence in $90 \%$ of tumors, leading to an $83.3 \%$ GTR rate $(108,109)$. In a follow up study expanding upon this initial experience, Hohne et al. found a 95\% fluorescence rate in 95 patients, with an $86 \%$ rate of no residual contrast enhancement. In this series, lung adenocarcinoma, melanoma and renal cell carcinoma were the only primary cancers that did not consistency exhibit fluorescein fluorescence (110). As part of the FLUOCERTUM Prospective Study, 25 metastastic lesions were included, of which 24 showed heterogenous enhancement (111). From these primary experiences and others, fluorescein appears to be a reliable fluorophore for brain metastasis surgery. 
Second Window ICG technique appears to have advantages for visualization of brain metastasis as most of these tumors have a disrupted BBB and thus accumulate ICG (Figure 1). In a recent publication, Teng et al. demonstrated improved survival in patients with resection of all near infrared fluorescent signal in patients undergoing craniotomy for brain metastasis (112). In 47 patients who underwent resection of 51 metastatic lesions, all tumors demonstrated quantifiable NIR fluorescence with a mean SBR of 4.9. Diagnostic accuracy was improved by changing the threshold signal as compared to normal brain background, and a lack of residual NIR fluorescence not only predicted the postoperative MRI gadolinium findings but also predicted progression free survival at 1 year. ICG may prove to have its greatest role in resection of these tumors.

\section{Pediatric Brain Tumors}

Similar to the adult literature, maximal safe resection is the standard of care in pediatric HGG. However, unlike the adult literature, we lack randomized controlled trial data for using FGS in the treatment of pediatric brain tumors. The use of 5-ALA for brain tumor surgery in children was first reported by Ruge et al., where 5-ALA was used to resect in a 9-yearold with a right temporal lobe pleomorphic xantoastrocytoma (PXA) (113). There have been no large single center studies currently, however, in 78 patients among 20 European centers, Stummer et al. found that $85 \%$ HGG and $80 \%$ ependymomas showed fluorescence, and that most primitive neuro-ectodermal tumors (PNET), gangliogliomas, medulloblastomas and pilocytic astrocytomas did not fluoresce (70). Other studies have shown robust fluorescence in HGG, with inconsistent fluuoresence in medulloblastoma, which may be related to underlying subtype $(21,114)$. While the safety data for 5-ALA use has been wellestablished in the adult literature, it is less studied in pediatric patients, and there has prior suggestion of increased liver enzyme values with decreasing patient age (115). In a multicenter study of 24 pediatric patients, de Laurentis et al. found fluorescence in $77.8 \%$ of tumors, and found fluorescence to be "helpful" in half of the cases (116). BLZ-100 has recently shown to be safe and effective in the treatment of both HGG and LGG in adults, and is currently under investigation for pediatric brain tumors (60).

\section{Spinal Cord Intramedullary Tumors}

In the resection of intramedullary spinal cord tumors, establishing the margin between tumor and spinal cord is essential to minimize the risk of spinal cord injury. Ependymomas and astrocytomas, two of the most common intramedullary tumors, both have robust uptake of 5-ALA, and therefore it has studied for this use. Gross total resection of ependymomas is especially crucial, as it is a potentially curable lesion. The first series of intramedullary ependymomas using 5-ALA was published in 2013, when Inoue et al. found that $77 \%$ of ependymomas demonstrated fluorescence, leading to a GTR in $80 \%$ of cases (117). In a study of 52 patients with 55 spinal tumors including 12 ependymomas, Millesi et al. found 5-ALA to be a safe and effective adjunct in cases of ependymomas, meningiomas, hemangiopericytomas and drop metastases, with a GTR rate of $75 \%$ ependymomas (118). With spinal astrocytomas, the margins are less defined, and surgeons are faced with a more difficult situation in where to end a subtotal resection, at the expense of sensorimotor function. 5-ALA may help in identifying tumor margins, and to aid in deciding where to limit cytoreduction, to preserve high-level functionality.

Fluorescein sodium has been shown to be effective for intramedullary tumors in several studies. Acerbi et al. found fluorescence in $82 \%$ of tumors, including ependymomas, hemangioblastomas, astrocytoma, and a glioneuronal tumor forming rosettes (119). In a study of 34 intradural extramedullary and 15 intramedullary lesions, surgeons found fluorescein helpful in delineating tumor from surrounding tissue in $96 \%$ cases (120).

ICG has additionally been used for intramedullary tumors, specifically vascular spinal cord lesions, such as hemangioblastoma and cavernous angioma (54). In these cases, identifying the feeding and draining veins of these tumors can help surgeons safely remove the lesion. In the case of cavernous angiomas, the surrounding spinal cord takes up the ICG fluorescence, however, the angioma remains avascular, providing surgeons with a nice margin for resection (121).

\section{Primary CNS Lymphoma and Stereotactic Biopsy}

Safety and accuracy are the two most important objectives for stereotactic biopsy of cerebral lesions. Fluorescein has been shown to be effective in predicting tumor pathology, especially in contrast-enhancing lesions (122), and in a proof-of-concept study, Lynagh et al. found that in vivo fluorescein signal was strongly predictive of tumor tissue, and could be used to identify tumor prior to biopsy (123). Additionally, 5-ALA and ICG have been shown to be effective in identifying tumoral vessels, and 5-ALA, ICG and fluorescein can accurately detect tumor tissue prior to biopsy (124). By coupling fluorescence with confocal microscopy, identifying tumor tissue may now be feasible in real time without a frozen section (124), and may even increase the diagnostic yield, with Malinova et al. finding that 5-ALA fluorescence had a higher sensitivity and negative predictive value for unclear cerebral pathologies compared to frozen section (125). Second Window ICG has also been successfully used in stereotactic biopsy procedures, to assure the surgeon that the contrast-enhancing portion of the tumor has been biopsied (126).

Several case series have shown a potential role for 5-ALA PpIX fluorescence in primary CNS lympoma $(127,128)$. Lymphoma may mimic HGG radiographically, and therefore PpIX and other fluorophores have been used in cases of presumed HGG. However, the standard of care for primary CNS lymphoma is chemotherapy and radiotherapy following diagnostic biopsy (129), creating a potential role for 5-ALA in improving the diagnostic yield of lymphoma tissue. In the largest series to date on stereotactic biopsies for primary CNS lymphoma, Yamamoto et al. found that 34 of 41 lesions showed fluorescent signal, with a true-positive rate of $82.9 \%$ (128). Kiesel et al. found fluorescence in $79 \%$ primary lymphoma lesions, and it has recently been proposed that if a lesion demonstrates strong fluorescence, that it may not require intraoperative histopathology, potentially making biopsies safer by decreasing number of biopsy samples 
and reducing length of stay (130). Fluorescein has also been used to effectively delinate lymphoma tissue vs. normal brain in two case series, where lesions were preoperatively diagnosed as HGG $(47,108)$. Further study is required to better understand the role for fluorescein in primary CNS lymphoma. In addition, Second Window ICG accumulates dramatically as expected in primary CNS lymphoma, and may be effective in identifying this tissue for biopsy (131).

\section{Other Tumors and Pathological Conditions Requiring Surgery}

In addition to the aforementioned CNS tumors, there are several other tumor types that have been studied in the FGS literature.

Peripheral nerve sheath tumors (PNST), comprised of mostly schwannomas, may be difficult to distinguish from surrounding tissues, allowing for a potential role for FGS guidance. In a series of 25 PNST, Vetrano et al. found that fluorescein showed fluorescence in 13 of 14 schwannomas, and allowed for further resection leading to a GTR in six neurofibroma cases and one schwannoma case (132). In a series by Marbacher et al. of 458 tumors receiving 5-ALA PpIX, zero of seven schwannomas showed fluorescence (133). To our knowledge, there have not been studied conducted evaluating SWIG for these tumors.

Sellar tumors, in particular pituitary adenomas, have not been reported to demonstrate strong fluorescent signal, and therefore, not much research has been studied on these tumors. In the Marbacher et al. series, only one of 12 pituitary adenomas demonstrated fluorescence (133). Falco et al. found fluorescence in one of one patients studies in the FLUOCERTUM cohort (111). The role of SWIG in these lesions may be limited, as the pituitary gland is a normal structure that fluoresces with ICG (54). Despite this potential limitaions, ICG endoscopy has been proposed for resection of skull base surgery, and techniques for use have been described (134), with distinguishable margins able to be identified in both functional and non-functional pituitary lesions (135).

Hemangioblastomas may be an important tumor for FGS, as subtotal resection may lead to local recurrence, and FGS may help visualize the intramural nodule within the associated peritumoral

\section{REFERENCES}

1. Brown TJ, Brennan MC, Li M, Church EW, Brandmeir NJ, Rakszawski KL, et al. Association of the extent of resection with survival in glioblastoma: a systematic review and meta-analysis. JAMA Oncol. (2016) 2:14609. doi: 10.1001/jamaoncol.2016.1373

2. Fernandes C, Costa A, Osório L, Lago RC, Linhares P, Carvalho B, et al. Current Standards of Care in Glioblastoma Therapy. Glioblastoma: Codon Publications. (2017).

3. Haj A, Doenitz C, Schebesch KM, Ehrensberger D, Hau P, Putnik $\mathrm{K}$, et al. Extent of resection in newly diagnosed glioblastoma: impact of a specialized neuro-oncology care center. Brain Sci. (2018) 8:5. doi: 10.3390/brainsci8010005

4. Yamada S, Muragaki Y, Maruyama T, Komori T, Okada Y. Role of neurochemical navigation with 5 -aminolevulinic acid during intraoperative cyst. As part of the FLUOCERTUM prospective study of 279 patients receiving fluorescein-guided tumor resection, seven patients with hemangioblastoma were included, all of which demonstrated fluorescence (111). Utsuki et al. used 5-ALA fluorescence, and showed strong fluorescence in all nine hemangioblastoma cases (136). The use of ICG has been rarely reported for both brain and intramedullary hemangioblastoma resections $(137,138)$.

Several other tumor types have shown potential promise in FGS, such as strong fluorescence observed in fourth ventricle subependymomas (139), germ cell tumors undergoing endoscopic biopsy (140). Further research is warranted on these rarer tumors, to better understand which fluorophores may be implored for use.

\section{CONCLUSION}

Understanding the administration and properties of the various fluorophores used in glioma surgery is essential for its use as a surgical adjunct. Fluorophores may target areas of bloodbrain barrier breakdown, areas of inflammation, or specifically glioma cells. Fluorophores are administered by different routes, and surgeons should be aware of the relationship between fluorophore administration and tumor fluorescence. ICG and fluorescein work by passive targeting, and have the benefit of IV administration in the operating room within seconds (ICG as vascular angiography agent) to a couple hours (fluorescein), to the next day (Second Window ICG as an EPR accumulated agent). As an oral agent, 5-ALA is consumed prior to anesthseia, and is able to persist in target tissue for longer, allowing for logistical delays. Newly studied molecular targets, such as BLZ100 and EGFR conjugates, are also given in the operating room, but may last in tumor tissue for up to several days.

\section{AUTHOR CONTRIBUTIONS}

AS and $\mathrm{CH}$ : conceptualization and investigation. AS, MR, $\mathrm{NM}, \mathrm{RB}, \mathrm{JL}, \mathrm{FA}$, and $\mathrm{CH}$ : writing-original draft preparation, writing-review, and editing. AS: visualization. $\mathrm{CH}$ : supervision and project. All authors have read and agreed to the published version of the manuscript.
MRI-guided resection of intracranial malignant gliomas. Clin Neurol Neurosurg. (2015) 130:134-9. doi: 10.1016/j.clineuro.2015.01.005

5. Zhang ZZ, Shields LB, Sun DA, Zhang YP, Hunt MA, Shields CB. The art of intraoperative glioma identification. Front Oncol. (2015) 5:175. doi: 10.3389/fonc.2015.00175

6. Su X, Huang Q-F, Chen H-L, Chen J. Fluorescence-guided resection of high-grade gliomas: a systematic review and meta-analysis. Photodiagn Photodyn Therapy. (2014) 11:451-8. doi: 10.1016/j.pdpdt.2014. 08.001

7. Neira JA, Ung TH, Sims JS, Malone HR, Chow DS, Samanamud JL, et al. Aggressive resection at the infiltrative margins of glioblastoma facilitated by intraoperative fluorescein guidance. J Neurosurg. (2016) 127:11122. doi: 10.3171/2016.7.JNS16232

8. Stummer W, Pichlmeier U, Meinel T, Wiestler OD, Zanella F, Reulen HJ, et al. Fluorescence-guided surgery with 5-aminolevulinic acid for resection of 
malignant glioma: a randomised controlled multicentre phase III trial. Lancet Oncol. (2006) 7:392-401. doi: 10.1016/S1470-2045(06)70665-9

9. Hadjipanayis CG, Stummer W. Fluorescence-Guided Neurosurgery: NeuroOncology and Cerebrovascular Applications. New York, NY: Thieme. (2019). doi: 10.1055/b-0038-164181

10. Stummer W, Stocker S, Novotny A, Heimann A, Sauer O, Kempski O, et al. In vitro and in vivo porphyrin accumulation by C6 glioma cells after exposure to 5-aminolevulinic acid. J Photochem Photobiol B. (1998) 45:160-9. doi: 10.1016/S1011-1344(98)00176-6

11. Hadjipanayis CG, Widhalm G, Stummer W. What is the surgical benefit of utilizing 5-aminolevulinic acid for fluorescenceguided surgery of malignant gliomas? Neurosurgery. (2015) 77:663-73. doi: 10.1227/NEU.0000000000000929

12. Bottomley, S. S. Pathophysiology of heme synthesis. Semin Hematol. (1988) 25:282-302.

13. Onda N, Kimura M, Yoshida T, Shibutani M. Preferential tumor cellular uptake and retention of indocyanine green for in vivo tumor imaging. Int J Cancer. (2016) 139:673-82. doi: 10.1002/ijc.30102

14. Francaviglia N, Iacopino DG, Costantino G, Villa A, Impallaria P, Meli F, et al. Fluorescein for resection of high-grade gliomas: a safety study control in a single center and review of the literature. Surg Neurol Int. (2017) 8:17. doi: 10.4103/sni.sni_89_17

15. Cho SS, Salinas R, Lee JY. Indocyanine-green for fluorescence-guided surgery of brain tumors: evidence, techniques, and practical experience. Front Surg. (2019) 6:11. doi: 10.3389/fsurg.2019.00011

16. Okuda T, Yoshioka H, Kato A. Fluorescence-guided surgery for glioblastoma multiforme using high-dose fluorescein sodium with excitation and barrier filters. J Clin Neurosci. (2012) 19:1719-22. doi: 10.1016/j.jocn.2011.12.034

17. Haglund MM, Hochman DW, Spence AM, Berger MS. Enhanced optical imaging of rat gliomas and tumor margins. Neurosurgery. (1994) 35:93041. doi: 10.1227/00006123-199411000-00019

18. Acerbi F, Broggi M, Broggi G, Ferroli P. What is the best timing for fluorescein injection during surgical removal of high-grade gliomas? Acta Neurochir. (2015) 157:1377-8. doi: 10.1007/s00701-015-2455-Z

19. Senders JT, Muskens IS, Schnoor R, Karhade AV, Cote DJ, Smith TR, et al. Agents for fluorescence-guided glioma surgery: a systematic review of preclinical and clinical results. Acta Neurochir. (2017) 159:15167. doi: 10.1007/s00701-016-3028-5

20. Zeh R, Sheikh S, Xia L, Pierce J, Newton A, Predina J, et al. The second window ICG technique demonstrates a broad plateau period for near infrared fluorescence tumor contrast in glioblastoma. PLOS ONE. (2017) 12:e0182034. doi: 10.1371/journal.pone.0182034

21. Zhang C, Boop FA, Ruge J. The use of 5-aminolevulinic acid in resection of pediatric brain tumors: a critical review. J Neurooncol. (2019) 141:56773. doi: 10.1007/s11060-018-03004-y

22. Eyüpoglu IY, Hore N, Fan Z, Buslei R, Merkel A, Buchfelder M, et al. Intraoperative vascular DIVA surgery reveals angiogenic hotspots in tumor zones of malignant gliomas. Sci Rep. (2015) 5:1-7. doi: 10.1038/srep07958

23. Haglund MM, Berger MS, Hochman DW. Enhanced optical imaging of human gliomas and tumor margins. Neurosurgery. (1996) 38:30817. doi: 10.1097/00006123-199602000-00015

24. Hansen DA, Spence AM, Carski T, Berger MS. Indocyanine green (ICG) staining and demarcation of tumor margins in a rat glioma model. Surg. Neurol. (1993) 40:451-6. doi: 10.1016/0090-3019(93)90046-4

25. Martirosyan NL, Cavalcanti DD, Eschbacher JM, Delaney PM, Scheck AC, Abdelwahab MG, et al. Use of in vivo near-infrared laser confocal endomicroscopy with indocyanine green to detect the boundary of infiltrative tumor: laboratory investigation. J Neurosurg. (2011) 115:11318. doi: 10.3171/2011.8.JNS11559

26. Maeda H, Tsukigawa K, Fang J. A retrospective 30 years after discovery of the enhanced permeability and retention effect of solid tumors: next-generation chemotherapeutics and photodynamic therapy-problems, solutions, and prospects. Microcirculation. (2016) 23:173-82. doi: 10.1111/micc. 12228

27. Lee JY, Thawani JP, Pierce J, Zeh R, Martinez-Lage M, Chanin $\mathrm{M}$, et al. Intraoperative near-infrared optical imaging can localize gadolinium-enhancing gliomas during surgery. Neurosurgery. (2016) 79:856-71. doi: 10.1227/NEU.0000000000001450
28. Cho SS, Salinas R, De Ravin E, Teng CW, Li C, Abdullah KG, et al. Near-infrared imaging with second-window indocyanine green in newly diagnosed high-grade gliomas predicts gadolinium enhancement on postoperative magnetic resonance imaging. Mol Imaging Biol. (2020) 22:1427-37. doi: 10.1007/s11307-019-01455-x

29. Moore GE, Peyton WT. The clinical use of fluorescein in neurosurgery; the localization of brain tumors. J Neurosurg. (1948) 5:392-8. doi: 10.3171/jns.1948.5.4.0392

30. Schebesch K, Brawanski A, Hohenberger C, Hohne J. Fluorescein sodium-guided surgery of malignant brain tumors: history, current concepts, and future projects. Turkish Neurosurg. (2016) 26:185-94. doi: 10.5137/1019-5149.JTN.16952-16.0

31. Acerbi F, Broggi M, Eoli M, Anghileri E, Cavallo C, Boffano C, et al. Is fluorescein-guided technique able to help in resection of high-grade gliomas? Neurosurg Focus. (2014) 36:E5. doi: 10.3171/2013.11.FOCUS13487

32. Diaz RJ, Dios RR, Hattab EM, Burrell K, Rakopoulos P, Sabha N, et al. Study of the biodistribution of fluorescein in glioma-infiltrated mouse brain and histopathological correlation of intraoperative findings in highgrade gliomas resected under fluorescein fluorescence guidance. J Neurosurg. (2015) 122:1360-9. doi: 10.3171/2015.2.JNS132507

33. Shinoda J, Yano H, Yoshimura S, Okumura A, Kaku Y, Iwama T, et al. Fluorescence-guided resection of glioblastoma multiforme by using highdose fluorescein sodium: technical note. J Neurosurg. (2003) 99:597603. doi: $10.3171 /$ jns.2003.99.3.0597

34. Valli D, Belykh E, Zhao X, Gandhi S, Cavallo C, Martirosyan NL, et al. Development of a simulation model for fluorescence-guided brain tumor surgery. Front Oncol. (2019) 9:748. doi: 10.3389/fonc.2019.00748

35. Acerbi F, Broggi M, Schebesch KM, Höhne J, Cavallo C, De Laurentis $\mathrm{C}$, et al. Fluorescein-guided surgery for resection of high-grade gliomas: a multicentric prospective phase II study (FLUOGLIO). Clin Cancer Res. (2018) 24:52-61. doi: 10.1158/1078-0432.CCR-17-1184

36. Belykh E, Miller EJ, Patel AA, Yazdanabadi MI, Martirosyan NL, Yagmurlu $\mathrm{K}$, et al. Diagnostic accuracy of a confocal laser endomicroscope for in vivo differentiation between normal injured and tumor tissue during fluoresceinguided glioma resection: laboratory investigation. World Neurosurg. (2018) 115:e337-48. doi: 10.1016/j.wneu.2018.04.048

37. Ichioka $\mathrm{T}$, Miyatake $\mathrm{S}$, Asai $\mathrm{N}$, Kajimoto $\mathrm{Y}$, Nakagawa $\mathrm{T}$, Hayashi $\mathrm{H}$, et al. Enhanced detection of malignant glioma xenograft by fluorescein-human serum albumin conjugate. J Neurooncol. (2004) 67:47-52. doi: 10.1023/B:NEON.0000021783.62610.1b

38. Martirosyan NL, Eschbacher JM, Kalani MY, Turner JD, Belykh E, Spetzler RF, et al. Prospective evaluation of the utility of intraoperative confocal laser endomicroscopy in patients with brain neoplasms using fluorescein sodium: experience with 74 cases. Neurosurg Focus. (2016) 40:E11. doi: 10.3171/2016.1.FOCUS15559

39. Kuroiwa T, Kajimoto Y, Ohta T. Development of a fluorescein operative microscope for use during malignant glioma surgery: a technical note and preliminary report. Surg Neurol. (1998) 50:41-9. doi: 10.1016/S0090-3019(98)00055-X

40. Chen B, Wang H, Ge P, Zhao J, Li W, Gu H, et al. Gross total resection of glioma with the intraoperative fluorescence-guidance of fluorescein sodium. Int J Med Sci. (2012) 9:708-14. doi: 10.7150/ijms.4843

41. Roberts DW, Olson J. Fluorescein guidance in glioblastoma resection. $N$ Engl J Med. (2017) 376:e36. doi: 10.1056/NEJMicm1611258

42. Bowden SG, Neira JA, Gill, B. J. A., Ung TH, Englander ZK, Zanazzi $\mathrm{G}$, et al. Sodium fluorescein facilitates guided sampling of diagnostic tumor tissue in non-enhancing gliomas. Neurosurgery. (2018) 82:71927. doi: 10.1093/neuros/nyx271

43. Belykh E, Shaffer KV, Lin C, Byvaltsev VA, Preul MC, Chen L. Blood-brain barrier, blood-brain tumor barrier, and fluorescence-guided neurosurgical oncology: delivering optical labels to brain tumors. Front Oncol. (2020) 10:739. doi: 10.3389/fonc.2020.00739

44. Koc K, Anik I, Cabuk B, Ceylan S. Fluorescein sodium-guided surgery in glioblastoma multiforme: a prospective evaluation. Br J Neurosurg. (2008) 22:99-103. doi: 10.1080/02688690701765524

45. Schebesch KM, Proescholdt M, Höhne J, Hohenberger C, Hansen E, Riemenschneider MJ, et al. Sodium fluorescein-guided resection under the YELLOW $560 \mathrm{~nm}$ surgical microscope filter in malignant brain 
tumor surgery-a feasibility study. Acta Neurochir. (2013) 155:6939. doi: 10.1007/s00701-013-1643-y

46. Zhang DY, Singhal S, Lee JYK. Optical principles of fluorescence-guided brain tumor surgery: a practical primer for the neurosurgeon. Neurosurgery. (2019) 85:312-24. doi: 10.1093/neuros/nyy315

47. Hamamcioglu MK, Akçakaya MO, Göker B, Kasimcan MÖ, Kiriş T. The use of the YELLOW $560 \mathrm{~nm}$ surgical microscope filter for sodium fluorescein-guided resection of brain tumors: our preliminary results in a series of 28 patients. Clin Neurol Neurosurg. (2016) 143:3945. doi: 10.1016/j.clineuro.2016.02.006

48. Suero Molina E, Wölfer J, Ewelt C, Ehrhardt A, Brokinkel B, Stummer W. Dual-labeling with 5 -aminolevulinic acid and fluorescein for fluorescenceguided resection of high-grade gliomas: technical note. J Neurosurg. (2018) 128:399-405. doi: 10.3171/2016.11.JNS161072

49. Ung TH, Kellner C, Neira JA, Wang SH, D’Amico R, Faust PL, et al. The use of fluorescein sodium in the biopsy and gross-total resection of a tectal plate glioma. J Neurosurg Pediatr. (2015) 16:7325. doi: 10.3171/2015.5.PEDS15142

50. Xiang Y, Zhu XP, Zhao JN, Huang GH, Tang JH, Chen HR, et al. Blood-brain barrier disruption, sodium fluorescein, and fluorescence-guided surgery of gliomas. $\mathrm{Br} \quad J$ Neurosurg. (2018) 32:141-8. doi: 10.1080/02688697.2018.1428731

51. Folaron M, Strawbridge R, Samkoe KS, Filan C, Roberts DW, Davis SC. Elucidating the kinetics of sodium fluorescein for fluorescence-guided surgery of glioma. J Neurosurg. (2018) 131:724-34. doi: 10.3171/2018.4.JNS172644

52. Stummer W, Tonn JC, Goetz C, Ullrich W, Stepp H, Bink A, et al. 5-Aminolevulinic acid-derived tumor fluorescence: the diagnostic accuracy of visible fluorescence qualities as corroborated by spectrometry and histology and postoperative imaging. Neurosurgery. (2014) 74:3109. doi: 10.1227/NEU.0000000000000267

53. Maragkos GA, Schupper AJ, Lakomkin N, Sideras P, Price G, Baron $\mathrm{RB}$, et al. Fluorescence-guided high-grade glioma surgery more than $4 \mathrm{~h}$ after 5-aminolevulinic acid administration. Front Neurol. (2021) 2021:644804. doi: 10.3389/fneur.2021.644804

54. Hadjipanayis CG, Stummer W. Fluorescence-guided neurosurgery: neurooncology and cerebrovascular applications. Thieme. (2019).

55. Hadjipanayis CG, Stummer W. 5-ALA and FDA approval for glioma surgery. Neurooncol. (2019) 141:479-86. doi: 10.1007/s11060-019-03098-y

56. Stummer W, Novotny A, Stepp H, Goetz C, Bise K, Reulen HJ. Fluorescenceguided resection of glioblastoma multiforme by using 5 -aminolevulinic acid-induced porphyrins: a prospective study in 52 consecutive patients. $J$ Neurosurg. (2000) 93:1003-13. doi: 10.3171/jns.2000.93.6.1003

57. Teixidor P, Arráez MÁ, Villalba G, Garcia R, Tardáguila M, González JJ, et al. Safety and efficacy of 5-aminolevulinic acid for high grade glioma in usual clinical practice: a prospective cohort study. PLoS ONE. (2016) 11:e0149244. doi: 10.1371/journal.pone.0149244

58. Center for Drug Evaluation and Research. Aminolevulinic Acid Hydrochloride, Known as ALA $\mathrm{HCl}$ (Gleolan, NX Development Corp.) as an Optical Imaging Agent Indicated in Patients With Gliomas. (2017). Available online at: https://www.fda.gov/drugs/resources-informationapproved-drugs/aminolevulinic-acid-hydrochloride-known-ala-hclgleolan-nx-development-corp-optical-imaging-agent (accessed June 3, 2020).

59. Kaneko S, Suero Molina E, Ewelt C, Warneke N, Stummer W. Fluorescencebased measurement of real-time kinetics of protoporphyrin IX after 5aminolevulinic acid administration in human in situ malignant gliomas. Neurosurgery. (2019) 85:E739-46. doi: 10.1093/neuros/nyz129

60. Patil CG, Walker DG, Miller DM, Butte P, Morrison B, Kittle DS, et al. Phase 1 safety, pharmacokinetics, and fluorescence imaging study of tozuleristide (BLZ-100) in adults with newly diagnosed or recurrent gliomas. Neurosurgery. (2019) 85:E641-9. doi: 10.1093/neuros/nyz125

61. Weichert JP, Clark PA, Kandela IK, Vaccaro AM, Clarke W, Longino MA, et al. Alkylphosphocholine analogs for broad-spectrum cancer imaging and therapy. Sci Transl Med. (2014) 6:240ra75. doi: $10.1126 /$ scitranslmed.3007646

62. Swanson KI, Clark PA, Zhang RR, Kandela IK, Farhoud M, Weichert JP, et al. Fluorescent cancer-selective alkylphosphocholine analogs for intraoperative glioma detection. Neurosurgery. 76:115-24. doi: 10.1227/NEU.0000000000000622

63. Seekell K, Lewis S, Wilson C, Li S, Grant G, Wax A. Feasibility study of brain tumor delineation using immunolabeled gold nanorods. Biomed. Opt. Express. (2013) 4:2284-95. doi: 10.1364/BOE.4.002284

64. Davis SC, Samkoe KS, O'Hara JA, Gibbs-Strauss SL, Payne HL, Hoopes PJW, et al. MRI-coupled fluorescence tomography quantifies EGFR activity in brain tumors. Acad Radiol. (2010) 17:271-6. doi: 10.1016/j.acra.2009.11.001

65. Samkoe KS, Gunn JR, Marra K, Hull SM, Moodie KL, Feldwisch J, et al. Toxicity and pharmacokinetic profile for single-dose injection of ABY-029: a fluorescent anti-EGFR synthetic affibody molecule for human use. Mol Imaging Biol. (2017) 19:512-21. doi: 10.1007/s11307-016-1033-y

66. de Souza AL, Marra K, Gunn J, Samkoe KS, Hoopes PJ, Feldwisch J, et al. Fluorescent affibody molecule administered in vivo at a microdose level labels EGFR expressing glioma tumor regions. Mol Imaging Biol. (2017) 19:41-8. doi: 10.1007/s11307-016-0980-7

67. Warram JM, de Boer E, Korb M, Hartman Y, Kovar J, Markert $\mathrm{JM}$, et al. Fluorescence-guided resection of experimental malignant glioma using cetuximab-IRDye 800 CW. Br J Neurosurg. (2015) 29:8508. doi: 10.3109/02688697.2015.1056090

68. Miller SE, Tummers WS, Teraphongphom N, van den Berg NS, Hasan A, Ertsey RD, et al. First-in-human intraoperative near-infrared fluorescence imaging of glioblastoma using cetuximab-IRDye800. J Neurooncol. (2018) 139:135-43. doi: 10.1007/s11060-018-2854-0

69. Schipmann S, Schwake M, Suero Molina E, Stummer W. Markers for identifying and targeting glioblastoma cells during surgery. J Neurol Surg A Cent Eur Neurosurg. (2019) 80:475-87. doi: 10.1055/s-0039-1692976

70. Stummer W, Rodrigues F, Schucht P, et al. Predicting the "usefulness" of 5-ALA-derived tumor fluorescence for fluorescence-guided resections in pediatric brain tumors: a European survey. Acta Neurochir. (2014) 156:231524. doi: 10.1007/s00701-014-2234-2

71. Zhao S, Wu J, Wang C, Liu H, Dong X, Shi C, et al. Intraoperative fluorescence-guided resection of high-grade malignant gliomas using 5-aminolevulinic acid-induced porphyrins: a systematic review and meta-analysis of prospective studies. PLoS ONE. (2013) 8:e63682. doi: 10.1371/journal.pone.0063682

72. Eljamel S. 5-ALA fluorescence image guided resection of glioblastoma multiforme: a meta-analysis of the literature. Int J Mol Sci. (2015) 16:1044356. doi: 10.3390/ijms160510443

73. Diez Valle R, Tejada Solis S, Idoate Gastearena MA, Garcia de Eulate R, Dominguez Echavarri P, and Aristu Mendiroz, J. Surgery guided by 5aminolevulinic fluorescence in glioblastoma: volumetric analysis of extent of resection in single-center experience. J Neurooncol. (2011) 102:10513. doi: $10.1007 / \mathrm{s} 11060-010-0296-4$

74. Lau D, Hervey-Jumper SL, Chang S, Molinaro AM, McDermott MW, Phillips JJ, et al. A prospective Phase II clinical trial of 5aminolevulinic acid to assess the correlation of intraoperative fluorescence intensity and degree of histologic cellularity during resection of highgrade gliomas. J Neurosurg. (2016) 124:1300-9. doi: 10.3171/2015.5. JNS1577

75. Idoate MA, Diez Valle R, Echeveste J, Tejada S. Pathological characterization of the glioblastoma border as shown during surgery using 5-aminolevulinic acid-induced fluorescence. Neuropathology. (2011) 31:575-82. doi: 10.1111/j.1440-1789.2011.01202.x

76. Roberts DW, Valdés PA, Harris BT, Fontaine KM, Hartov A, Fan X, et al. Coregistered fluorescence-enhanced tumor resection of malignant glioma: relationships between delta-aminolevulinic acid-induced protoporphyrin IX fluorescence, magnetic resonance imaging enhancement, and neuropathological parameters. Clinical article. J Neurosurg. (2011) 114:595-603. doi: 10.3171/2010.2.JNS091322

77. Aldave G, Tejada S, Pay E, Marigil M, Bejarano B, Idoate MA, et al. Prognostic value of residual fluorescent tissue in glioblastoma patients after gross total resection in 5-aminolevulinic Acid-guided surgery. Neurosurgery. (2013) 72:915-20. doi: 10.1227/NEU.0b013e31828c3974

78. Rey-Dios R, Hattab EM, Cohen-Gadol AA. Use of intraoperative fluorescein sodium fluorescence to improve the accuracy of tissue diagnosis during stereotactic needle biopsy of high-grade gliomas. Acta Neurochir. (2014) 156:1071-5. doi: 10.1007/s00701-014-2097-6 
79. Jakola AS, Myrmel KS, Kloster R, Torp SH, Lindal S, Unsgård G, et al. Comparison of a strategy favoring early surgical resection vs. a strategy favoring watchful waiting in low-grade gliomas. JAMA. (2012) 308:18818. doi: 10.1001/jama.2012.12807

80. Smith JS, Chang EF, Lamborn KR, Chang SM, Prados MD, Cha S, et al. Role of extent of resection in the longterm outcome of low-grade hemispheric gliomas. J Clin Oncol. (2008) 26: 1338-45. doi: 10.1200/JCO.2007.13.9337

81. Teng L, Nakada M, Zhao SG, Endo Y, Furuyama N, Nambu E, et al. Silencing of ferrochelatase enhances 5-aminolevulinic acid-based fluorescence and photodynamic therapy efficacy. Br J Cancer. (2011) 104:798-807. doi: 10.1038/bjc.2011.12

82. Hefti M, von Campe G, Moschopulos M, Siegner A, Looser H, Landolt H. 5aminolevulinic acid induced protoporphyrin IX fluorescence in high-grade glioma surgery: a one-year experience at a single institutuion. Swiss Med Wkly. (2008) 138:180-5.

83. Utsuki S, Oka H, Sato S, Suzuki S, Shimizu S, Tanaka S, et al. Possibility of using laser spectroscopy for the intraoperative detection of non-fluorescing brain tumors and the boundaries of brain tumor infiltrates. Technical note. $J$ Neurosurg. (2006) 104:618-20. doi: 10.3171/jns.2006.104.4.618

84. Widhalm G, Wolfsberger S, Minchev G, Woehrer A, Krssak M, Czech T, et al. 5-Aminolevulinic acid is a promising marker for detection of anaplastic foci in diffusely infiltrating gliomas with non-significant contrast enhancement. Cancer. (2010) 116:1545-52. doi: 10.1002/cncr.24903

85. Jaber M, Wölfer J, Ewelt C, Holling M, Hasselblatt M, Niederstadt T, et al. The value of 5-aminolevulinic acid in lowgrade gliomas and highgrade gliomas lacking glioblastoma imaging features: an analysis based on fluorescence, magnetic resonance imaging, $18 \mathrm{~F}$-fluoroethyl tyrosine positron emission tomography, and tumor molecular factors. Neurosurgery. (2016) 78:401-11. doi: 10.1227/NEU.0000000000001020

86. Paulus W, Peiffer J. Intratumoral histologic heterogeneity of gliomas, A quantitative study. Cancer. (1989) 64:442-7. doi: 10.1002/10970142(19890715)64:2<442::AID-CNCR2820640217>3.0.CO;2-S

87. Widhalm G, Kiesel B, Woehrer A, Traub-Weidinger T, Preusser M, Marosi C, et al. 5-Aminolevulinic acid induced fluorescence is a powerful intraoperative marker for precise histopathological grading of gliomas with non-significant contrast-enhancement. PLoS ONE. (2013) 8:e76988. doi: 10.1371/journal.pone.0076988

88. Kamp MA, Krause Molle Z, Munoz-Bendix C, Rapp M, Sabel M, Steiger HJ, et al. Various shades of red-a systematic analysis of qualitative estimation of ALA-derived fluorescence in neurosurgery. Neurosurg Rev. (2018) 41:318. doi: 10.1007/s10143-016-0745-4

89. Millesi M, Kiesel B, Mischkulnig M, Martínez-Moreno M, Wöhrer A, Wolfsberger S, et al. Analysis of the surgical benefits of 5-ALAinduced fluorescence in intracranial meningiomas: experience in 204 meningiomas. J Neurosurg. (2016) 125:1408-19. doi: 10.3171/2015.12. JNS151513

90. Della Puppa A, Rustemi O, Gioffrè G, Troncon I, Lombardi G, Rolma $\mathrm{G}$, et al. Predictive value of intraoperative 5-aminolevulinic acid-induced fluorescence for detecting bone invasion in meningioma surgery. $J$ Neurosurg. (2014) 120:840-5. doi: 10.3171/2013.12.JNS131642

91. Eicker SO, Floeth FW, Kamp M, Steiger HJ, Hänggi D. The impact of fluorescence guidance on spinal intradural tumour surgery. Eur Spine J. (2013) 22:1394-401. doi: 10.1007/s00586-013-2657-0

92. d'Avella E, Volpin F, Manara R, Scienza R, Della Puppa A. Indocyanine green videoangiography (ICGV)-guided surgery of parasagittal meningiomas occluding the superior sagittal sinus (SSS). Acta Neurochir. (2013) 155:41520. doi: 10.1007/s00701-012-1617-5

93. Ueba T, Okawa M, Abe $H$, Nonaka $M$, Iwaasa $M$, Higashi $T$, et al. Identification of venous sinus, tumor location, and pial supply during meningioma surgery by transdural indocyanine green videography. $J$ Neurosurg. (2013) 118:632-6. doi: 10.3171/2012.11.JNS121113

94. Han SJ, Magill ST, Tarapore PE, Horton JC, McDermott MW. Direct visualization of improved optic nerve pial vascular supply following tuberculum meningioma resection: case report. J Neurosurg. (2016) 125:5659. doi: 10.3171/2015.6.JNS15765

95. Lee JYK, Pierce JT, Thawani JP, Zeh R, Nie S, Martinez-Lage M, et al. Nearinfrared fluorescent image-guided surgery for intracranial meningioma. $J$ Neurosurg. (2018) 128:380-90. doi: 10.3171/2016.10.JNS161636
96. Akçakaya MO, Göker B, Kasimcan MÖ, Hamamcioglu MK, Kiriş T. Use of sodium fluorescein in meningioma surgery performed under the YELLOW$560 \mathrm{~nm}$ surgical microscope filter: feasibility and preliminary results. World Neurosurg. (2017) 107:966-73. doi: 10.1016/j.wneu.2017.07.103

97. Eschbacher J, Martirosyan NL, Nakaji P, Sanai N, Preul MC, Smith $\mathrm{KA}$, et al. In vivo intraoperative confocal microscopy for real-time histopathological imaging of brain tumors. J Neurosurg. (2012) 116:85460. doi: 10.3171/2011.12.JNS11696

98. Al-Shamy G, Sawaya R. Management of brain metastases: the indispensable role of surgery. J Neurooncol. (2009) 92:27582. doi: 10.1007/s11060-009-9839-y

99. Kamp MA, Rapp M, Bühner J, Slotty PJ, Reichelt D, Sadat $\mathrm{H}$, et al. Early postoperative magnet resonance tomography after resection of cerebral metastases. Acta Neurochir. (2015) 157:1573-80. doi: 10.1007/s00701-015-2479-4

100. Patchell RA, Tibbs PA, Walsh JW, Dempsey RJ, Maruyama $\mathrm{Y}$, Kryscio RJ, et al. A randomized trial of surgery in the treatment of single metastases to the brain. N Engl J Med. (1990) 322:494-500. doi: 10.1056/NEJM199002223220802

101. Gamarra F, Lingk P, Marmarova A, Edelmann M, Hautmann H, Stepp H, et al. 5-Aminolevulinic acid-induced fluorescence in bronchial tumours: dependency on the patterns of tumour invasion. J Photochem Photobiol B. (2004) 73:35-42. doi: 10.1016/j.jphotobiol.2003.09.009

102. Moan J, Bech O, Gaullier JM, Stokke T, Steen HB, Ma LW, et al. Protoporphyrin IX accumulation in cells treated with 5-aminolevulinic acid: dependence on cell density, cell size and cell cycle. Int J Cancer. (1998) 75:134-9. doi: 10.1002/(SICI)1097-0215(19980105)75:1<134::AID-IJC20>3. $0 . \mathrm{CO} ; 2-\mathrm{F}$

103. Riedl CR, Daniltchenko D, Koenig F, Simak R, Loening SA, Pflueger H. Fluorescence endoscopy with 5-aminolevulinic acid reduces early recurrence rate in superficial bladder cancer. J Urol. (2001) 165:11213. doi: 10.1016/S0022-5347(05)66442-7

104. Tsai T, Ji HT, Chiang PC, Chou RH, Chang WS, Chen CT. ALA-PDT results in phenotypic changes and decreased cellular invasion in surviving cancer cells. Lasers Surg Med. (2009) 41:305-15. doi: 10.1002/lsm.20761

105. Utsuki S, Miyoshi N, Oka H, Miyajima Y, Shimizu S, Suzuki S, et al. Fluorescence-guided resection of metastatic brain tumors using a 5aminolevulinic acid-induced protoporphyrin IX: pathological study. Brain Tumor Pathol. (2007) 24:53-5. doi: 10.1007/s10014-007-0223-3

106. Marhold F, Mercea PA, Scheichel F, Berghoff AS, Heicappell P, Kiesel B, et al. Detailed analysis of 5-aminolevulinic acid induced fluorescence in different brain metastases at two specialized neurosurgical centers: experience in 157 cases. J Neurosurg. (2019) 27:1-12. doi: 10.3171/2019.6.JNS1997

107. Kamp MA, Grosser P, Felsberg J, Slotty PJ, Steiger HJ, Reifenberger G, et al. 5-aminolevulinic acid (5-ALA)-induced fluorescence in intracerebral metastases: a retrospective study. Acta Neurochir. (2012) 154:2238. doi: 10.1007/s00701-011-1200-5

108. Schebesch KM, Hoehne J, Hohenberger C, Acerbi F, Broggi M, Proescholdt $\mathrm{M}$, et al. Fluorescein sodium-guided surgery in cerebral lymphoma. Clin Neurol Neurosurg. (2015) 139:125-8. doi: 10.1016/j.clineuro.2015.09.015

109. Schebesch KM, Hoehne J, Hohenberger C, Proescholdt M, Riemenschneider MJ, Wendl C, et al. Fluorescein sodium-guided resection of cerebral metastases-experience with the first 30 patients. Acta Neurochir. (2015) 157:899-904. doi: 10.1007/s00701-015-2395-7

110. Höhne J, Hohenberger C, Proescholdt M, Riemenschneider MJ, Wendl C, Brawanski A, et al. Fluorescein sodium-guided resection of cerebral metastases-an update. Acta Neurochir. (2017) 159:363-7. doi: 10.1007/s00701-016-3054-3

111. Falco J, Cavallo C, Vetrano IG, de Laurentis C, Siozos L, Schiariti $\mathrm{M}$, et al. Fluorescein application in cranial and spinal tumors enhancing at preoperative MRI and operated with a dedicated filter on the surgical microscope: preliminary results in 279 patients enrolled in the FLUOCERTUM prospective study. Front Surg. (2019) 6:49. doi: 10.3389/fsurg.2019.00049

112. Teng CW, Cho SS, Singh Y, De Ravin E, Somers K, Buch L, et al. Second window ICG predicts gross-total resection and progressionfree survival during brain metastasis surgery. J Neurosurg. (2021) 2:110. doi: $10.3171 / 2020.8$.JNS201810 
113. Ruge JR, Liu J. Use of 5-aminolevulinic acid for visualization and resection of a benign pediatric brain tumor. J Neurosurg Pediatr. (2009) 4:4846. doi: 10.3171/2009.6.PEDS08428

114. Preuss M, Renner C, Krupp W, Christiansen H, Fischer L, Merkenschlager $\mathrm{A}$, et al. The use of 5-aminolevulinic acid fluorescence guidance in resection of pediatric brain tumors. Childs Nerv Syst. (2013) 29:12637. doi: 10.1007/s00381-013-2159-8

115. Offersen CM, Skjoeth-Rasmussen J. Evaluation of the risk of liver damage from the use of 5-aminolevulinic acid for intra-operative identification and resection in patients with malignant gliomas. Acta Neurochir. (2017) 159:145-50. doi: 10.1007/s00701-016-3014-y

116. de Laurentis C, Höhne J, Cavallo C, Restelli F, Falco J, Broggi $\mathrm{M}$, et al. The impact of fluorescein-guided technique in the surgical removal of CNS tumors in a pediatric population: results from a multicentric observational study. J Neurosurg Sci. (2019) 63:679-87. doi: 10.23736/S0390-5616.19.04601-0

117. Inoue $T$, Endo $T$, Nagamatsu $K$, Watanabe $M$, Tominaga $T$. 5aminolevulinic acid fluorescence-guided resection of intramedullary ependymoma: report of 9 cases. Neurosurgery. (2013) 72:ons15968. doi: 10.1227/NEU.0b013e31827bc7a3

118. Millesi M, Kiesel B, Woehrer A, Hainfellner JA, Novak K, MartínezMoreno $\mathrm{M}$, et al. Analysis of 5-aminolevulinic acid-induced fluorescence in 55 different spinal tumors. Neurosurg Focus. (2014) 36:E11. doi: 10.3171/2013.12.FOCUS13485

119. Acerbi F, Cavallo C, Schebesch KM, Akçakaya MO, de Laurentis C, Hamamcioglu MK, et al. Fluorescein-guided resection of intramedullary spinal cord tumors: results from a preliminary, multicentric, retrospective study. World Neurosurg. (2017) 108:603-9. doi: 10.1016/j.wneu.2017.09.061

120. Olguner SK, Arslan A, Açik V, Istemen I, Can M, Gezercan Y, et al. Sodium fluorescein for spinal intradural tumors. Front Oncol. (2021) 10:618579. doi: 10.3389/fonc. 2020.618579

121. Endo T, Aizawa-Kohama M, Nagamatsu K, Murakami K, Takahashi A, Tominaga T. Use of microscope-integrated near-infrared indocyanine green videoangiography in the surgical treatment of intramedullary cavernous malformations: report of eight cases. J Neurosurg Spine. (2013) 18:4439. doi: 10.3171/2013.1.SPINE12482

122. Nevzati E, Chatain GP, Hoffman J, Kleinschmidt-DeMasters BK, Lillehei KO, Ormond DR. Reliability of fluorescein-assisted stereotactic brain biopsies in predicting conclusive tissue diagnosis. Acta Neurochir. (2020) 162:19417. doi: 10.1007/s00701-020-04318-5

123. Lynagh R, Ishak M, Georges J, Lopez D, Osman H, Kakareka M, et al. Fluorescence-guided stereotactic biopsy: a proof-of-concept study. $J$ Neurosurg. (2019) 1-7.

124. Akshulakov SK, Kerimbayev TT, Biryuchkov MY, Urunbayev YA, Farhadi DS, Byvaltsev VA. Current Trends for improving safety of stereotactic brain biopsies: advanced optical methods for vessel avoidance and tumor detection. Front Oncol. (2019) 9:947. doi: 10.3389/fonc.2019.00947

125. Malinova V, von Eckardstein K, Mielke D, Rohde V. Diagnostic yield of fluorescence-assisted frame-based stereotactic biopsies of intracerebral lesions in comparison with frozen-section analysis. J Neurooncol. (2020) 149:315-23. doi: 10.1007/s11060-020-03608-3

126. Li C, Sullivan PZ, Cho S, Nasrallah MP, Buch L, Isaac Chen HC, et al. Intraoperative molecular imaging with second window indocyanine green facilitates confirmation of contrast-enhancing tissue during intracranial stereotactic needle biopsy: a case series. World Neurosurg. (2019) 126:e12118. doi: 10.1016/j.wneu.2019.02.231

127. Evers G, Kamp M, Warneke N, Berdel W, Sabel M, Stummer $\mathrm{W}$, et al. 5-aminolaevulinic acid-induced fluorescence in primary central nervous system lymphoma. World Neurosurg. (2017) 98:375-80. doi: 10.1016/j.wneu.2016.11.011

128. Yamamoto T, Ishikawa E, Miki S, Sakamoto N, Zaboronok A, Matsuda M, et al. Photodynamic diagnosis using 5 -aminolevulinic acid in 41 biopsies for primary central nervous system lymphoma. Photochem Photobiol. (2015) 91:1452-7. doi: 10.1111/php. 12510

129. Batchelor T, Loeffler JS. Primary CNS lymphoma. J Clin Oncol. (2006) 24:1281-8. doi: 10.1200/JCO.2005.04.8819
130. Millesi M, Kiesel B, Wöhrer A, Mercea PA, Bissolo M, Roetzer $\mathrm{T}$, et al. Is intraoperative pathology needed if 5-aminolevulinicacid-induced tissue fluorescence is found in stereotactic brain tumor biopsy? Neurosurgery. (2020) 86:366-73. doi: 10.1093/neuros/ nyz086

131. Henderson F Jr, Brem S, Hussain J, Buch L, Maloney E, Singhal S, et al. Second window indocyanine green localizes CNS lymphoma in real time in the operating room: report of two cases. Br J Neurosurg. (2020) 3:1-5. doi: 10.1080/02688697.2020.1716945

132. Vetrano IG, Acerbi F, Falco J, Devigili G, Rinaldo S, Messina $\mathrm{G}$, et al. Fluorescein-guided removal of peripheral nerve sheath tumors: a preliminary analysis of 20 cases. J Neurosurg. (2019) 6:1-10. doi: 10.3171/2019.9.JNS19970

133. Marbacher S, Klinger E, Schwyzer L, Fischer I, Nevzati E, Diepers $M$, et al. Use of fluorescence to guide resection or biopsy of primary brain tumors and brain metastases. Neurosurg Focus. (2014) 36:E10. doi: 10.3171/2013.12.FOCUS13464

134. Inoue A, Kohno S, Ohnishi T, Nishida N, Suehiro S, Nakamura Y, et al. Tricks and traps of ICG endoscopy for effectively applying endoscopic transsphenoidal surgery to pituitary adenoma. Neurosurg Rev. (2020). doi: 10.1007/s10143-020-01382-4

135. Amano K, Aihara Y, Tsuzuki S, Okada Y, Kawamata T. Application of indocyanine green fluorescence endoscopic system in transsphenoidal surgery for pituitary tumors. Acta Neurochir. (2019) 161:695-706. doi: 10.1007/s00701-018-03778-0

136. Utsuki S, Oka H, Kijima C, Miyajima Y, Hagiwara H, Fujii K. Utility of intraoperative fluorescent diagnosis of residual hemangioblastoma using 5- aminolevulinic acid. Neurol India. (2011) 59:612-5. doi: 10.4103/0028-3886.84349

137. Molina CA, Pennington Z, Ahmed AK, Westbroek E, Goodwin $\mathrm{ML}$, Tamargo $\mathrm{R}$, et al. Use of intraoperative indocyanine green angiography for feeder vessel ligation and en bloc resection of intramedullary hemangioblastoma. Oper Neurosurg. (2019) 17:573-9. doi: 10.1093/ons/opz053

138. Singh YB, Cho SS, Blue R, Teng CW, De Ravin E, Buch L, et al. Second-window indocyanine green for visualization of hemangioblastoma: a case report with two-dimensional operative video. Oper Neurosurg. (2021) 20:E229-33. doi: 10.1093/ons/opaa392

139. Bernal García LM, Cabezudo Artero JM, Marcelo Zamorano MB, Gilete Tejero, I. Fluorescence-guided resection with 5aminolevulinic acid of subependymomas of the fourth ventricle: report of 2 cases: technical case report. Neurosurgery. (2015) 11(suppl.2):E364-71. doi: 10.1227/NEU.0000000000000682

140. Takeda J, Nonaka M, Li Y, et al. 5-ALA fluorescence-guided endoscopic surgery for mixed germ cell tumors. J Neurooncol. (2017). 134:11924. doi: 10.1007/s11060-017-2494-9

Conflict of Interest: $\mathrm{CH}$ is a consultant for NX Development Corporation (NXDC) and Synaptive Medical. NXDC, a privately held company, markets Gleolan (5-ALA, aminolevulinic acid hydrochloride). Gleolan is an optical imaging agent approved for the visualization of malignant tissue during glioma surgery. $\mathrm{CH}$ is a consultant for NXDC and receives royalty payments for the sale of Gleolan, has also received speaker fees by Carl Zeiss and Leica. FA has received speaker's fees from Carl Zeiss Meditec, Oberkochen, Germany.

The remaining authors declare that the research was conducted in the absence of any commercial or financial relationships that could be construed as a potential conflict of interest.

Copyright (C) 2021 Schupper, Rao, Mohammadi, Baron, Lee, Acerbi and Hadjipanayis. This is an open-access article distributed under the terms of the Creative Commons Attribution License (CC BY). The use, distribution or reproduction in other forums is permitted, provided the original author(s) and the copyright owner(s) are credited and that the original publication in this journal is cited, in accordance with accepted academic practice. No use, distribution or reproduction is permitted which does not comply with these terms. 